\title{
TRABALHO DOMÉSTICO REMUNERADO: CONTRADIÇÕES ESTRUTURANTES E EMERGENTES NAS RELAÇÕES SOCIAIS NO BRASIL
}

\author{
TRABAJO DOMÉSTICO REMUNERADO: \\ CONTRADICCIONES ESTRUCTURALES $\Upsilon$ EMERGENTES \\ EN LAS RELACIONES SOCIALES EN BRASIL \\ PAID DOMESTIC WORK: STRUCTURAL AND EMERGING \\ CONTRADICTIONS IN SOCIAL RELATIONS IN BRAZIL
}

\author{
Maria Betânia Ávila ${ }^{1}$ e Verônica Ferreira ${ }^{1}$
}

${ }^{1}$ SOS Corpo Instituto Feminista para a Democracia, Recife/PE, Brasil

RESUMO: Este artigo analisa o trabalho doméstico remunerado no Brasil buscando articular dimensões conjunturais e estruturais, a partir das determinações inscritas na divisão sexual e racial do trabalho, que o conformam como um campo de trabalho assalariado majoritariamente ocupado por mulheres e, dentre elas, por mulheres negras, e marcado por relações de exploração e dominação conformadas pela imbricação das relações sociais de gênero, raça e classe, que atravessam a formação social brasileira. Analisa-se como o trabalho doméstico remunerado se inscreve no cerne das contradições sociais do país e como a luta das trabalhadoras domésticas e cada momento de conquista advindo desta luta movimentam reações que expressam os conflitos e antagonismos sociais inerentes a estas relações.

PALAVRAS-CHAVE: Trabalho Doméstico; Emprego Doméstico; Relações Sociais; Lutas Sociais.

RESUMEN: Este artículo analiza el trabajo doméstico remunerado en Brasil, buscando articular dimensiones coyunturales y estructurales, a partir de las determinaciones inscritas en la división sexual y racial del trabajo, que lo configuran como un campo de trabajo asalariado ocupado sobretodo por mujeres y, entre ellas, mujeres negras, y marcado por relaciones de explotación y dominación formadas por la superposición de relaciones sociales de género, raza y clase, que cruzan la formación social brasileña. Analiza cómo el trabajo doméstico remunerado está en el centro de las contradicciones sociales del país y cómo la lucha de las trabajadoras domésticas y cada momento de conquista resultante de esta lucha mueve reacciones que expresan los conflictos y los antagonismos sociales inherentes a estas relaciones.

PALABRAS CLAVE: Trabajo doméstico; Empleo a domicilio; Relaciones sociales; Luchas sociales.

ABSTRACT: This article analyzes paid domestic work in Brazil, seeking to articulate conjunctural and structural dimensions based on the determinations inscribed in the sexual and racial division of labor, which make it up as a wage labor field mainly occupied by women and, among them, black women, and marked by relations of exploitation and domination shaped by the imbrication of social relations of gender, race and class that cross the Brazilian social formation. The article analyzes how paid domestic work is at the core of the country's social contradictions as well as how the struggle of domestic workers and each moment of conquest resulting from this struggle trigger reactions that express the conflicts and social antagonisms inherent in these relationships. KEYWORDS: Housework; Home Employment; Social relationships; Social struggles. 


\section{Introdução}

Do ponto de vista conceitual que adotamos, o trabalho doméstico compreende duas formas de relações de trabalho: o trabalho doméstico gratuito, feito na própria residência dos sujeitos que o realizam, majoritariamente mulheres, e o trabalho doméstico remunerado, realizado na residência alheia de patroas e patrões, e da mesma forma, majoritariamente realizado por mulheres e, no caso brasileiro, por mulheres negras. Nesse texto, desenvolveremos nossa análise tendo como foco o trabalho doméstico remunerado, pela sua importância social e histórica neste país, e pela situação política e social de exploração, dominação e apropriação que, sempre presentes em nossa realidade social, se desvelam de maneira contundente no contexto atual da pandemia de Covid-19. Também se considera que o emprego doméstico tem um peso extremamente importante no mercado de trabalho para as mulheres, especialmente entre as mulheres negras. As empregadas domésticas constituem uma das maiores categorias de trabalhadoras do país.

Um fato ocorrido no início da pandemia está pleno de significados sociais e históricos que se não explicam plenamente a sua ocorrência, que podem dar elementos para uma interpretação sobre as relações de trabalho doméstico no Brasil. Queremos nos referir ao fato de a primeira vítima letal da Covid-19, no Brasil, ter sido uma trabalhadora doméstica, empregada na casa de um casal que havia retornado naquele momento da Europa, de uma viagem na qual haviam contraído o vírus, o que não os impediu de convocar a presença da trabalhadora doméstica em sua casa, quando já se sabia desde antes que o contágio se faz de pessoa a pessoa e, portanto, o confinamento social seria como é fundamental para a prevenção individual e para evitar a catástrofe da contaminação coletiva.

Ainda queremos salientar que esse caso não é apenas um acontecimento a mais em uma determinada conjuntura. Devemos, portanto, ultrapassar a sua aparência fenomenológica de um fato isolado, desconectado das relações sociais que o determina. No Brasil,o novo coronavírus $(S A R S-C O V-2)$ foi trazido pela classe burguesa em suas viagens pelo mundo, e agora assola as populações trabalhadoras, sobretudo as mais empobrecidas, na sua maioria negra, e as populações indígenas. A desigualdade social abissal nesse país e a falta de políticas públicas para restringir os efeitos e a expansão da pandemia evidenciam o descaso do poder executivo no plano nacional pela saúde da população e, ao mesmo tempo, a condição geral de desproteção social e precarização do trabalho e das condições de vida produzidas pelo capitalismo neoliberal, exponenciadas no país desde o golpe de 2016, e a sequência de medidas de desestruturação dos direitos que constituem não sua consequência, mas a realização de seu propósito. Com a ascensão de Bolsonaro ao poder, esse projeto neoliberal passa a implementar-se por meio de um governo com fortes elementos fascistas e autocráticos. As atitudes deliberadas do presidente e outros membros do governo federal, transgressões pessoais aos protocolos de segurança de saúde e declarações contra as evidências e recomendações científicas sobre o problema, são fatores que levam ao aprofundamento da crise sanitária, que, associada à crise política, conformam uma tragédia de proporções incalculáveis.

Para conectar o fato narrado anteriormente da primeira vítima da Covid-19, queremos afirmar que é apenas na aparência que este se revela contingente. Todavia, em uma análise crítica de seu significado social, o que se revela é que esta morte está profundamente conectada com as relações de exploração e apropriação que conformam as relações de trabalho doméstico e nos demandam uma breve retomada dos seus determinantes históricos e sociais no país. 


\section{Trabalho doméstico na formação social brasileira}

Para entender as relações e as dinâmicas que conformam o trabalho doméstico no Brasil, é incontornável ter em conta as duas dimensões - remunerada e não remunerada -, uma vez que elas estão tanto na constituição das relações sociais de raça, classe e gênero, quanto na sua reprodução. Mais que isso, as relações de trabalho doméstico têm uma importância singular para compreendermos a formação social brasileira e as heranças coloniais - materiais, simbólicas e subjetivas - que estruturam a reprodução dessas relações e se expressam no contexto atual.

No Brasil, o emprego doméstico é historicamente indissociável da escravidão e do processo histórico de exploração, dominação e desapossamento da população negra pela classe burguesa, constitutiva da elite política, formada pelos senhores patriarcais brancos. Na busca da historicidade do trabalho doméstico remunerado, que conforma o que chamamos emprego doméstico, vamos encontrar que essa relação foi tecida no fio da história de uma sociedade fortemente marcada pela desigualdade. É a partir das relações sociais de sexo/gênero, de raça e de classe que o trabalho doméstico se conforma como um campo de trabalho assalariado no Brasil.

No período colonial, além de uma relação de profunda desigualdade e apropriação das mulheres, ter em suas residências empregadas domésticas consistia em um elemento de ostentação para marcar o poder de classe (Graham, 1992) e exibir o poder do senhor patriarcal branco e da sua família. A própria arquitetura das residências das classes média e burguesa no país aponta nesse último sentido mencionado. Em seu estudo, Lêda Maria Souza (1991) localiza no espaço arquitetônico do quarto da empregada doméstica, os vestígios ideológicos servis/escravocratas (Souza, 1991, p. 66) e, podemos acrescentar, também suas marcas materiais. Mesmo que na realidade de hoje as trabalhadoras domésticas remuneradas residam cada vez menos na casa das/os patroas/os, esse quarto localizado nos fundos dessas residências e em geral insalubres e usados como depósito, sendo ou não ocupado por uma trabalhadora, se mantém como parte do nosso "patrimônio" cultural racista e de classe, que define o padrão e as formas das residências das classes abastadas do país. Mesmo nas décadas mais recentes, marcadas pela redução no padrão de reprodução e rebaixamento salarial nas classes médias, que se expressa na diminuição do tamanho das residências, a dependência da empregada permanece como elemento de diferenciação de classe.

No contexto da pandemia de Covid-19, uma das expressões da persistência das relações de exploração e dominação das trabalhadoras domésticas remuneradas foi a pressão de empregadores(as) para manter a presença destas trabalhadoras em serviço no domicílios, no período do confinamento social necessário à proteção contra o alto nível de contágio do novo coronavírus. Esta pressão levou a que os governos estaduais do Pará e Pernambuco e a prefeitura de Belém incluíssem as trabalhadoras domésticas remuneradas no rol de serviços essenciais nos decretos de regulação das atividades econômicas e relações de trabalho no período de quarentena, o que foi denunciado pelas organizações de trabalhadoras de trabalhadoras e, em função dessa resistência, foi revertido ${ }^{1}$.

Na formação social brasileira, esse trabalho traz as marcas da servidão das mulheres como aptas e destinadas a servir compulsoriamente ao outro, e aos outros, e as marcas da escravidão a qual estiveram submetidas as mulheres negras no período colonial. No período escravocrata, não cabia o termo emprego doméstico no caso das mulheres negras, pois era na condição de escravas que elas faziam os trabalhos domésticos na casa das famílias 
dos senhores. Com o fim da escravidão, as mulheres negras passam a trabalhar como empregadas domésticas (Graham, 1992; Saffioti, 1979). Até hoje, as mulheres negras constituem a maioria dessa categoria. Mas além de serem majoritárias na categoria, há também uma forte conotação de preconceito e discriminação racial que impregna ideologicamente a representação do emprego doméstico no Brasil e que o associa a uma relação de "servidão" e a um trabalho de mulheres negras. Neste sentido, a servidão ganha mais um significado associado à escravidão, o que a nosso ver constitui uma particularidade brasileira. O sentido de servidão próprio do trabalho doméstico associado à concepção de que as mulheres estão intrinsecamente constituídas como seres disponíveis para servir aos outros está consubstancialmente informado pelo sentido de servidão próprio da escravidão da população negra, pois, como analisa Christiane Girard (1996), essa é uma relação de trabalho fortemente marcada pela história da escravidão das mulheres negras no país.

O desvelar dessas heranças contribui para a desnaturalização das relações de servitude no emprego doméstico, para explicar a presença majoritária das mulheres negras nesse trabalho e para legitimar, historicamente, a importância para a luta antirracista no país a luta das mulheres trabalhadoras, e das trabalhadoras domésticas em particular, e também para reafirmar um posicionamento do feminismo como movimento anti-patriarcal e antirracista e como dimensões incontornavelmente consubstanciais da sua práxis.

A magnitude do "serviço doméstico" assim como o sentido e as práticas que marcam essa relação de trabalho, como afirmado anteriormente, remonta ao período colonial. Caio Prado Júnior (1999), ao analisar a importância do trabalho servil na economia colonial, distingue dois setores importantes com "caracteres e consequências distintas" na formação da vida social brasileira, quais sejam, "o das atividades produtivas propriamente e as do serviço doméstico” (Prado, 1999, p. 278). Ressalta o autor que, embora a importância econômica do primeiro seja inegavelmente maior, o segundo não pode ser subestimado, por duas razões: "não só ele é numericamente volumoso... como é grande a participação que tem na vida social e a influência que sobre ela exerce. Nesse sentido, e excluído o elemento econômico, ele ultrapassa mesmo largamente o papel do outro setor" (Prado, 1999, p. 278).

Essa importância se revela, por exemplo, de maneira central, no campo da política. A resistência e a organização política das trabalhadoras se insurgem e, ao mesmo tempo, revelam, o autoritarismo que marca as relações sociais no país e estruturam as relações políticas. O emprego doméstico e o sujeito que o realiza, a empregada doméstica, converteram-se, na sociedade brasileira, numa poderosa expressão, e um elemento de sustentação do ponto de vista da ideologia dominante, do "mito fundador" (Chauí, 2000) que mascara uma profunda desigualdade e uma particular expressão das relações de mando e obediência e autoritarismo nas relações sociais tributárias da escravidão.

O trabalho doméstico remunerado se inscreve no cerne das contradições sociais do país, seja do ponto de vista histórico, seja como parte da resistência do povo negro e da classe trabalhadora, como na conjuntura atual, especialmente no contexto pós-conquista dos direitos trabalhistas, dentre os quais têm centralidade a regulamentação e a restrição da jornada de trabalho. A luta das trabalhadoras doméstica e cada momento de conquista advindo desta luta movimentam reações que expressam o conflito de gênero, raça e classe, e tornam assim evidentes as contradições e os antagonismos sociais inerentes a estas relações, ao mesmo tempo em que desconstroem todas as tentativas da classe dominante e branca de negar o racismo. 
Até 1972, as pessoas que trabalhavam como empregadas domésticas no Brasil não tinham qualquer direito trabalhista. Segundo o Sindicato dos Empregados Domésticos na Área Metropolitana da Cidade do Recife (1989):

Foi há mais ou menos trinta anos que começamos a descobrir a importância do nosso trabalho. Desde então, estamos nos organizando. Em 1972, tivemos uma primeira vitória. Depois de muitas discussões, estudos, abaixo-assinados, saiu a Lei n. 5.859, que garantiu três direitos importantes: o direito a ter carteira assinada, férias de vinte dias por ano e pagamento do IAPAS, o que garantiu aposentadoria e assistência médica. (Sindicato dos Empregados Domésticos na Área Metropolitana da Cidade do Recife, 1989, p. 8)

De acordo com as informações da Federação Nacional de Trabalhadoras Domésticas, em 2006 comemoraram-se 70 anos de organização dessa categoria, cujo marco inicial é a fundação da primeira Associação de Trabalhadoras Domésticas, por Laudelina de Campos Melo, em Santos, São Paulo, no ano de 1936.

Um avanço importante na cidadania dessa categoria se deu na Constituição de 1988, quando novos direitos foram conquistados a partir da organização dessas trabalhadoras:

Em 1987 começa a ser elaborada a nova Constituição, pelos senadores e deputados federais. Começamos então uma luta intensa para garantir uma legislação que reconhecesse nossa profissão e que nos igualasse aos outros trabalhadores. Fomos, neste período, uma das categorias profissionais mais presentes em Brasília... entregamos nas mãos do presidente daquela Assembleia, o deputado Ulysses Guimarães, um documento com nossas reivindicações. Elaboramos também uma "emenda popular" e conseguimos para ela dez mil assinaturas de apoio. Trabalhamos também em favor de outras emendas, como a da reforma agrária e a dos direitos das mulheres. (Sindicato dos Empregados Domésticos na Área Metropolitana da Cidade do Recife, 1989, s/p)

A partir da Constituição de 1988, além dos direitos adquiridos em 1972, as empregadas domésticas adquiriram os seguintes direitos trabalhistas: salário mínimo como piso salarial, décimo terceiro salário, folga semanal remunerada uma vez por semana (a lei recomenda o domingo, mas permite acordo), férias anuais de trinta dias, licença-gestante, aviso prévio proporcional e aposentadoria. Em 2015, no período de governo da presidenta Dilma Rousseff, a categoria conquistou a regulamentação desses direitos trabalhistas em um processo marcado por perdas e formas de precarização, já no bojo de um processo político que revelava as fraturas no interior do governo e os interesses de forças políticas que viriam a ser determinantes no golpe jurídico-institucional de 2016². Estes direitos, que não foram totalmente instalados como garantia e mediação das relações de trabalho no cotidiano, se tornaram mais vulneráveis como realidade concreta em suas vidas a partir da Reforma Trabalhista, aprovada em 2018, sob os desígnios da ordem neoliberal e no período do governo ilegítimo de Michel Temer, que assume a Presidência da República por meio de um golpe jurídico-parlamentar.

Na prática, a falta de valor do trabalho doméstico, que ainda persiste como dado da realidade social, configura-se como um problema político para a legitimação de sua luta por direitos, o que leva também à emergência de muitas dificuldades para a organização 
política da categoria. Por isso, como dito anteriormente, é parte da própria ação política a afirmação dos sujeitos como trabalhadoras e como parte da classe trabalhadora. Nesse sentido, a afirmação das empregadas domésticas como trabalhadoras organizadas recoloca desafios políticos para o movimento feminista e interpela a própria produção sociológica no campo da análise sobre as relações de trabalho. Como afirma Rivane Arantes (2019)

Assim, como um campo de luta, o trabalho doméstico no Brasil evidencia tanto a resistência das que estão em posição de inferioridade política, econômica e cultural, mas especificamente as mulheres, majoritariamente negras e absolutamente empobrecidas, pela reivindicação de democratização e transformação desses espaços como localizações não naturais, quanto a avidez com que as elites do país insistem em manter seu status quo e resistem a desnaturalizar os poderes que as mantêm em condição de dominação sobre aquelas. (Arantes, 2019, p. 36)

Em que pese a importância do emprego doméstico como problemática social, só recentemente, nos anos 1970, por meio dos estudos feministas sobre o trabalho doméstico não mercantil e a divisão sexual do trabalho em que se insere, é que o estudo do emprego doméstico ganhou maior investidura, formando-se, inclusive, os elementos teórico-políticos para a crítica das interpretações patriarcais em que fora abordado até então nas obras dos clássicos da formação social, econômica e política brasileira, exigindo uma reinterpretação desta formação que tome sua centralidade como expressão da imbricação das relações sociais de sexo, raça e classe nesse processo constitutivo (Farias, 1983; Girard, 1996; Kofes, 1982; Saffioti, 1979).

\section{Divisão sexual e racial do trabalho, trabalho doméstico remunerado e não remunerado}

O trabalho doméstico como uma atribuição das mulheres é um elemento estruturante da divisão sexual do trabalho. Segundo Danièle Kergoat (2001), essa divisão é definida em termos de uma "designação prioritária dos homens à esfera produtiva e das mulheres à esfera reprodutiva, como também, e simultaneamente, a captação pelos homens das funções com forte valor social agregado (políticos, religiosos, militares etc.)" (Kergoat, 2001, p. 89). Para esta autora, esta divisão também está baseada nos princípios da hierarquia e da separação.

O trabalho doméstico é uma forma histórica particular que toma o trabalho reprodutivo na sociedade capitalista, sendo esta forma inseparável da sociedade salarial (Kergoat, 2004). Essa construção histórica surgida e desenvolvida nos países centrais do capitalismo desde a colonização foi imposta como uma forma de organização social do trabalho, que hegemonizou a organização da vida cotidiana, excluiu e, em muitos casos, eliminou, e elimina ainda, outros modos de organização social do cotidiano e das formas de organizar a relação entre produção e reprodução, isto é, outros modos de "produção do viver", como define Helena Hirata (2002).

A gratuidade é o que configura, em primeiro plano, o sentido e a prática do trabalho doméstico, e é a partir da conexão entre gratuidade e atribuição das mulheres que a relação de trabalho doméstico remunerado vai se estabelecer como uma relação de classe e racial 
entre mulheres. $\mathrm{O}$ trabalho doméstico remunerado é uma relação de trabalho na qual as mulheres, responsáveis pelo trabalho doméstico gratuito em suas casas, repassam para outras mulheres, através de um pagamento, suas atribuições domésticas e, dessa forma, estabelece-se uma subdivisão, baseada em relações sociais de classe e raça, no interior da divisão sexual e racial do trabalho.

Para as mulheres, o trabalho remunerado produtivo ou reprodutivo e o trabalho reprodutivo não remunerado constituem uma relação de contradição a qual elas devem enfrentar como parte da vida cotidiana. As atividades produtivas e reprodutivas no cotidiano constituem um processo contraditório. A partir dessa contradição, é importante analisar os bloqueios e as interdições que são geradas para as mulheres no cotidiano. Essas contradições negam com contundência qualquer tentativa de abordar essa relação - trabalho doméstico não remunerado e trabalho profissional, realizados pelas mulheres - em termos de uma conciliação.

As mulheres da classe trabalhadora, e as empregadas domésticas como parte dela, estão sujeitas a jornadas de trabalho extensivas, intensivas, intermitentes (Ávila, 2009) e, para muitas trabalhadoras, também simultâneas, geradas pela dinâmica entre trabalho produtivo e reprodutivo, e no caso dessas trabalhadoras, jornadas de trabalho reprodutivo em suas casas e trabalho reprodutivo remunerado.

Dentro das contradições dessa relação de classe e raça entre mulheres, a apropriação do tempo de trabalho se desvela como um elemento central. O trabalho doméstico é uma demanda sempre incessante: quanto mais o tempo de trabalho da empregada doméstica é expropriado, mais liberado do trabalho doméstico se torna o tempo das patroas e patrões. Dessa forma, o trabalho das empregadas domésticas pode diminuir as tensões da divisão sexual do trabalho nos espaços familiares onde trabalham, mas não alteram essa divisão e, ao contrário, é um elemento da sua constituição e reprodução. Atuam, ainda, na dinâmica de reprodução social ampliada mediada pelo Estado, que se beneficia da expropriação da trabalhadora doméstica na medida em que isto reduz a pressão por serviços públicos e se traduz, na prática, no modelo em que as demandas do trabalho reprodutivo são resolvidas pela mercantilização de serviços e pela desoneração do Estado (Ferreira, 2017).

No contex to atual, as mulheres estão cada vez mais inseridas no mercado de trabalho, sem que isso signifique uma alteração na sua relação com o trabalho doméstico não remunerado. Quando as mulheres procuram os meios para exercer um trabalho remunerado, uma atividade política, ou outras atividades externas ao seu domicílio, e às vezes até mesmo dentro dele, elas buscam formas de liberação do trabalho doméstico não remunerado. Uma delas é construir como parte do cotidiano uma rede de relações quase exclusivamente entre mulheres para enfrentar as necessidades de presença e ausência entre as esferas do trabalho remunerado e não remunerado. As desigualdades de classe e raça entre mulheres são, historicamente, um determinante da sua inserção na relação trabalho doméstico/ trabalho assalariado. O trabalho doméstico sempre foi de responsabilidade das mulheres, para as mulheres de todas as classes. Há, no entanto, uma desigualdade social histórica na forma de enfrentar essa relação. Para as mulheres trabalhadoras, no geral, as jornadas de trabalho são extensivas, intensivas e intermitentes entre trabalho remunerado e trabalho doméstico gratuito. O que leva a uma exploração do tempo de trabalho muito mais aguda.

A contratação de uma trabalhadora doméstica é uma prática amplamente instalada, e, evidentemente, está estabelecida com base nas relações de gênero, classe e de raça. Como afirma Rivane Arantes (2019), “o trabalho doméstico continua sendo a principal 
porta de entrada das mulheres no mercado de trabalho no Brasil. Esta é uma realidade particular para as mulheres negras e empobrecidas, que seguem como a maioria nessa categoria" (Arantes, 2019, p. 29). No contexto atual, as contradições engendradas pelo trabalho doméstico aumentam com a hegemonia das políticas neoliberais que desestruturam e/ou eliminam políticas sociais de apoio às necessidades e à reprodução da vida cotidiana.

Consideramos que o trabalho doméstico, gratuito ou assalariado, significa, como objetivação da capacidade de trabalho de alguém e como processo de subjetivação, um desafio para o desenvolvimento das pesquisas no campo do trabalho. As desigualdades sociais entre as mulheres produzem uma relação trabalhista entre elas marcada por uma exploração da força de trabalho, que não pode ser definida em termos da exploração para a produção de mais-valia, mas que necessita de definição como uma forma de exploração específica, que aqui está sendo tratada em termos de expropriação do tempo de trabalho, da energia da pessoa, da sua capacidade de criação, da inteligência, de condições precárias nas quais o trabalho é exercido e da sua, em geral, baixa remuneração. Mesmo que a empregada doméstica trabalhe para todo o grupo familiar, a patroa é, por tradição, a mulher, geralmente denominada de "a dona da casa". As tarefas que a empregada doméstica realiza estão dentro da divisão sexual do trabalho como parte do trabalho das mulheres, isto é, como aquelas que são de responsabilidade da mulher-mãe, dona de casa, esposa.

Quando as mulheres patroas, através da contratação do trabalho de outras mulheres, se liberam do tempo do trabalho doméstico, parcial ou integralmente, com tudo mais que isso significa, se faz a possibilidade de liberar o uso do seu tempo diário para outras atividades, para acessar o mundo do trabalho assalariado, a esfera pública, para descansar, cuidar de si, estudar etc., sem, no entanto, mexer com a estrutura da divisão sexual do trabalho. Daí o conflito de interesses se desloca para a relação entre mulheres, e os homens se mantêm como exteriores às responsabilidades do trabalho doméstico. $\mathrm{O}$ trabalho doméstico se mantém como uma questão de mulheres, e a relação de dominação/exploração entre homens e mulheres se reproduz e se imbrica com as relações sociais de raça.

\section{Trabalho doméstico remunerado e desafios históricos e atuais para os estudos e as luta no campo do trabalho}

Como afirmado anteriormente, uma análise do emprego doméstico no Brasil nos remete a questões históricas que remontam ao período colonial e desafiam os estudos e interpretações das relações sociais no Brasil contemporâneo.

O emprego doméstico incorpora tempos históricos diferenciados. De um lado, sua inserção no campo da cidadania como um emprego que já foi reconhecido como portador de direitos, ainda que só tenha alcançada a plenitude dos direitos trabalhistas em 2013, e ainda não seja de fato uma realidade no cotidiano de trabalho dessas trabalhadoras. Com a reforma trabalhista em 2016, o acesso a esses direitos se tornou ainda mais difícil e, como para toda classe trabalhadora, com vários níveis de flexibilização que abrem caminho para a prática do trabalho precário com respaldo legal.

A busca por uma casa, como seu espaço próprio e de sua família, foi uma dimensão fundamental das lutas e da construção da cidadania para essa categoria de trabalhadoras. Foi e é também uma forma de esforço e determinação individual que impacta tanto o cotidiano como a reestruturação da trajetória de vida. A partir de nossa experiência de 
pesquisa com trabalhadoras domésticas (Ávila, 2009; Ávila, Ferreira, \& Arantes, 2016; Ferreira, 2017), podemos afirmar que ter um "teto todo seu" (Woolf, 1928) se mostrou, na nossa interpretação, como uma dimensão na construção da sua autonomia através da qual se alcança um patamar mínimo de emancipação do jugo patronal, no qual o sujeito se apropria não só de uma parte do uso do seu tempo no cotidiano mas, indo além disso, se apropria simbolicamente e subjetivamente de si mesma. O espaço da sua vida particular se desloca do espaço na qual está presente como estranha e subalterna, que é o espaço daqueles e daquelas que pertencem a uma outra classe social à qual não pertence, para um espaço seu e localizado no contexto social de sua própria classe, ela deixa de ser uma estranha na casa em que reside.

Utilizamos a ideia de emancipação a partir de Philippe Zarifian (2002), que a toma como um movimento, de acordo com sua leitura do conceito de emancipação em Marx. Para Zarifian (2002), a opressão é o poder de escravizar ou dominar, e a "emancipação é o reverso, a destruição desse poder” (Zarifian, 2002, p. 66). No ato de passagem entre a casa alheia e a sua própria casa, acontece em alguma dimensão uma ruptura objetiva, com implicações subjetivas, ante as interdições mais profundas para se tornar cidadã.

A conquista da jornada de trabalho regulada e as reações que despertaram entre empregadores e empregadoras são também reveladoras deste fio histórico entre o Brasil contemporâneo e colonial na relação de trabalho no emprego doméstico. Somente em 2013 as empregadas domésticas conquistaram o direito a uma jornada de trabalho regulamentada de 44 horas semanais, como os demais trabalhadores(as). Segundo pesquisa do DIEESE, em Recife, a jornada média semanal das empregadas domésticas mensalistas chegava a 53 horas semanais - a mais longa registrada dentre as regiões metropolitanas do país (DIEESE, 2013). A regulamentação da jornada significa, para as trabalhadoras, a disposição objetiva de mais tempo para sua vida, com a redução das jornadas, e a ruptura objetiva e subjetiva com o princípio da disponibilidade permanente como condição do trabalho doméstico em geral reproduzida no trabalho doméstico não remunerado. Carrega, portanto, um sentido emancipatório.

As práticas de assédio sexual de patrões são ainda hoje registradas, ao passo que seguem naturalizadas como manifestações mesmas do "bom convívio" entre grupos sociais - estão aí as novelas a romancear sistematicamente essas práticas. A empregada doméstica retratada como "parte da família", apesar da forte denúncia feita pelas organizações de trabalhadoras domésticas, é ainda uma imagem frequentemente utilizada e um discurso recorrente, em geral acionado para descaracterizar a relação de trabalho e, por consequência, os direitos a ela associados.

Todas estas contradições estão reavivadas com o processo recente de desmonte de direitos, e no cenário pós-pandemia prefigura-se o aviltamento de práticas de exploração e retrocessos na relação de trabalho.

A pandemia trouxe muitas para dentro das casas de patroas por exigências patronais, fazendo retroceder, mesmo que de forma temporária, um direito adquirido e vivido como uma experiência de cidadania fundamental. Independentemente do tempo de duração dessa situação, ela também revela a relação de poder e desapropriação que segue sendo praticada nesta relação de trabalho. Para reduzir a possibilidade de contágio de empregadores e empregadoras, é possível que práticas de controle e “assepsia” ostensivamente discriminatórias sejam práticas comuns implementadas por empregadoras e empregadores. Se o vírus foi trazido por empregadores e empregadoras de trabalhadoras domésticas 
e a partir daí se espraiou para as periferias, a realidade da desigualdade social no país já evidencia que é nas periferias que o vírus seguirá circulando, dadas as condições de vida. Por sua vez, o caminho de volta da periferia aos bairros nobres será necessariamente interditado pela constituição de diferentes fronteiras e barreiras políticas e sociais. Esta interdição para que o vírus não inverta sua rota original, pode muito possivelmente recair sobre o corpo da trabalhadora doméstica, por meio de práticas de controle da mobilidade urbana baseadas na classe, na raça, e no gênero. Especialmente em um contexto como o que estamos atravessando, de autorização governamental para o exercício das práticas de mando, discriminação e expropriação ditadas pelas classes abastadas nas relações de trabalho e em todas as esferas da vida social.

As grandes transformações deveriam ser consideradas a partir da possibilidade que elas tiveram ou venham a ter para inscrever na vida cotidiana um novo sentido e novas condições sociais para a vida humana. Nesse encontro entre o cotidiano e a história, a conquista de direitos sociais, econômicos, políticos e ambientais, são entendidos não só na sua importância crucial para condições de vida cidadã e com plenas possibilidades de bem-estar, mas também como parte de uma luta de resistência e transformação dentro de uma relação de temporalidade de curto, médio e longos prazos. E por que não dizer também uma relação profunda com as formas de alterar um passado de injustiças sociais, o qual deve ser superado na sua totalidade, mas jamais apagado como memória histórica.

A ruptura com as interdições subjetivas e objetivas que produzem os bloqueios dos movimentos dos sujeitos entre os espaços da vida cotidiana e aqueles nos quais se tem acesso à ação coletiva transformadora, na nossa concepção, pode ser considerada uma base sobre a qual se sustenta o processo de democratização das relações sociais, uma vez que possibilita a emergência do sujeito como agente desse processo. Os processos vividos nos diferentes momentos estão perpassados por relações sociais e pessoais de poder. A desigualdade de poder no manejo da vida cotidiana pode ser um instrumento de bloqueio para uma grande parte das mulheres. Onde há bloqueio, há restrição de liberdade que pode causar a destruição dos movimentos de que a cidadania necessita para se realizar e transformar a realidade social.

$\mathrm{Na}$ atual conjuntura, de acirramento das contradições sociais históricas pela ascensão neoliberal, conservadora e autoritária no país, a luta das trabalhadoras domésticas se inscreve no coração da resistência democrática a partir de uma perspectiva que considera a democracia uma forma de organização da vida social e que passa, necessariamente, pela transformação das relações e a organização social do trabalho, remunerado e não remunerado, produtivo e reprodutivo.

A organização, a resistência e a luta das mulheres trabalhadoras, e em particular das trabalhadoras domésticas, na sua maioria negra, em aliança com outros movimentos sociais e especialmente com o movimento feminista e de mulheres negras, dos quais também são sujeitos, para transformar as estruturas patriarcais, racistas e capitalistas e as relações sociais que as reproduzem, são os caminhos trilhados para alterar essa realidade social, conquistando e reconquistando direitos para construir um devir emancipatório. 


\section{Notas}

1 Para mais informações sobre estes fatos, ver Estados como Pará e Pernambuco classificaram serviço doméstico como atividade essencial, expondo inúmeras mulheres racializadas à doença. Recuperado de https://www.cartacapital.com.br/blogs/sororidade-em-pauta/ na-pandemia-por-que-servico-domestico-e-classificado-como-essencial/

Sindicato critica estados que incluíram domésticas em serviço essencial na quarentena. Recuperado de https://www.brasildefato.com.br/2020/05/25/ sindicato-critica-estados-que-incluiram-domesticas-em-servico-essencial-na-quarentena

2 Sobre o golpe jurídico-parlamentar de 2016, ver Singer, A., Jinkings, I., Kim, D., Cleto, M. (Orgs.). (2016). Por que gritamos golpe? Para entender o impeachment e a crise. São Paulo: Boitempo.

\section{Referências}

Arantes, R. F. M.A. (2019). El trabajo doméstico en Brasil en el proceso de desinstitucionalización de la frágil "democracia” brasileña después de 2016. In L. Celiberti, Lilian (Coord.), La Mesa Está Servida. La lucha de las trabajadoras domésticas en Argentina, Brasil, Paraguay, Perú y Uruguay (pp. 31-56). Montevideo: Edición AFM Cotidiano Mujer.

Ávila, M. B. (2009). O tempo do trabalho das empregadas domésticas: tensões entre dominação/ exploração e resistência. Recife: UFPE.

Ávila, M. B. (2016). O tempo do trabalho doméstico remunerado: entre cidadania e servidão. In A. R. P. Abreu, H. Hirata, \& M. R. Lombardi (Orgs.), Gênero e trabalho no Brasil e na França: perspectivas interseccionais (pp. 137-146). São Paulo: Boitempo.

Ávila, M. B., Ferreira, V., \& Arantes, R. (2016). Trabalho e Autonomia Econômica das Mulheres: uma análise crítica. Recife: Edições SOS Corpo.

Chauí, M. (2000). Brasil: mito fundador e sociedade autoritária. São Paulo: Fundação Perseu Abramo.

DIEESE - Departamento Intersindical de Estudos Sócio-Econômicos. (2013). O emprego doméstico no Brasil. Série Estudos e Pesquisas, 68. São Paulo: Autor. Recuperado de https:// www.dieese.org.br/estudosetorial/2013/estPesq68empregoDomestico.pdf

Farias, Z. A. (1983). Domesticidade: Cativeiro Feminino. Rio de Janeiro: Achiamé/CMB.

Ferreira, V. M. (2017). Apropriação do tempo de trabalho das mulheres nas políticas de saúde e reprodução social: uma análise de suas tendências. Tese de Doutorado, Programa de Pós-graduação em Serviço Social, Universidade Federal de Pernambuco, Recife, PE.

Girard, C. (1996). Citoyenneté et Culture de la Domesticité des Femmes Noires au Brésil. In B. Marques-Pereira \& A. Carrier (Orgs.), La Citoyenneté social des femmes au Brésil. Action colective, reproduction, informalité et domesticité (pp. 147-155) Bruxelles: L'Harmattan.

Graham, S. L. (1992). Proteção e obediência, criadas e seus patrões no Rio de Janeiro 1860-1910. São Paulo: Companhia das Letras. 
Hirata, H. (2002). Nova divisão sexual do trabalho? Um olhar voltado para empresa e a sociedade. São Paulo: Boitempo.

Kergoat, D. (2001). Le rapport social de sexe - De la reproduction des rapports sociaux à leur subversion. Actuel Marx, 30, 85-100.

Kergoat, D. (2004). Travail (le concept de). In H. Hirata, H. Le Doaré, D. Senotier et al. Dictionnaire critique du féminisme (pp. 243-248). Paris: Presses Universitaires de France.

Kofes, M. S. (1982). Entre Nós, Mulheres: Elas, as Patroas e Elas, as Empregadas. In M. S. Kofes et. al. (Orgs.), Colcha de Retalhos-Estudos sobre a Família no Brasil (pp. 183-193). São Paulo: Brasiliense.

Prado, C. (1999). Formação do Brasil Contemporâneo. São Paulo: Brasiliense

Saffioti, H. I. B. (1979). Emprego doméstico e capitalismo. Rio de Janeiro: Avenir.

Sindicato dos Empregados Domésticos da Área Metropolitana da Cidade do Recife. (1989). Domésticas: Uma categoria da classe trabalhadora, seus direitos, suas lutas, suas propostas. Recife: SOS CORPO.

Souza, L. M. T. (1991). Dependência de empregada: o espaço da exclusão. Dissertação de Mestrado, Programa de Pós-graduação em Serviço Social, Universidade Federal de Pernambuco, Recife, PE.

Woolf, V. (1928). Um teto todo seu. São Paulo: Círculo do Livro.

Zarifian, P. (2002). Marx, la qualification et le rapport social de sexe. Cahiers du Genre, 32, 63-85.

\section{MARIA BETÂNIA ÁVIILA \\ https://orcid.org/0000-0001-9449-3851}

SOS CORPO Instituto Feminista para a Democracia. Doutora em Sociologia pela Universidade Federal de Pernambuco - UFPE.

Endereço: Rua Real da Torre, 593, Madalena. Recife, PE.

E-mail: betania@soscorpo.org.br

\section{VERÔNICA FERREIRA}

\section{https://orcid.org/0000-0002-0753-9223}

SOS CORPO Instituto Feminista para a Democracia; Mestrado Acadêmico em Serviço Social, Trabalho e Questão Social - MASS da Universidade Estadual do Ceará - UECE/Doutora em Serviço Social pela Universidade Federal de Pernambuco - UFPE.

E-mail: veronica@soscorpo.org.br 


\begin{tabular}{|c|c|}
\hline Histórico & $\begin{array}{l}\text { Submissão: 19/06/2020 } \\
\text { Revisão: 16/07/2020 } \\
\text { Aceite:17/07/2020 }\end{array}$ \\
\hline $\begin{array}{l}\text { Contribuição } \\
\text { dos autores }\end{array}$ & $\begin{array}{l}\text { Concepção: MBA; VF. } \\
\text { Coleta de dados: Não se aplica. } \\
\text { Análise de dados: Não se aplica. } \\
\text { Elaboração do manuscrito: MBA; VF. } \\
\text { Revisões críticas de conteúdo intelectual importante: } \\
\text { MBA; VF. } \\
\text { Aprovação final do manuscrito: MBA; VF. }\end{array}$ \\
\hline $\begin{array}{l}\text { Consentimento } \\
\text { de uso de imagem }\end{array}$ & Não se aplica. \\
\hline $\begin{array}{l}\text { Aprovação, ética } \\
\text { e consentimento }\end{array}$ & Não se aplica. \\
\hline Financiamento & $\begin{array}{l}\text { Verônica Ferreira é bolsista de pós-doutorado da CAPES (Prêmio Capes } \\
\text { de Tese 2018). }\end{array}$ \\
\hline
\end{tabular}

